\title{
Solid Organ Transplantation: An Introduction to the Special Section
}

\author{
Zeeshan Butt ${ }^{1}$
}

Published online: 3 September 2015

(C) Springer Science+Business Media New York 2015

Several months ago, the editor-in-chief of the Journal of Clinical Psychology in Medical Settings, Dr. Jerry Leventhal, asked me to consider serving as guest editor for a special section highlighting the roles of the psychologist in solid organ transplantation and living donation. My initial reaction, honestly, was to refuse as politely as possible. But Jerry is nothing if not persistent, and for that I thank him. The more I thought about it, the more appealing the opportunity seemed.

My own entry into transplant psychology approximately 7 years ago was not planned or deliberate; in fact, it was quite serendipitous. Once it became clear that I would be spending more of my research and clinical time in transplant, I read as much as I could on transplant psychology. While there were several excellent papers and books to meet my needs at that time, most were written at a more advanced level. As I thought more about developing a special section for JCPMS, I wanted to invite papers that would represent a wide breadth of work, while providing readers unfamiliar with transplant with enough context to appreciate the psychologists' actual and potential role in this complex specialty area.

Thanks to the authors who contributed to this special section, I believe we have met that goal. The section begins with an article by Dr. Jared Skillings and Amber Lewandowski, who provide an excellent overview of the administrative, regulatory, and clinical processes for solid organ

Zeeshan Butt

z-butt@northwestern.edu

1 Departments of Medical Social Sciences, Surgery, \& Psychiatry and Behavioral Sciences, Northwestern University Feinberg School of Medicine, 633 N Saint Clair Street, 19th Floor, Chicago, IL 60611, USA transplantation in the US, with specific focus on biopsychosocial assessment and care of transplant candidates. Drs. Kristin Kuntz, Stephan Weinland, and I extend the overview provided in the Skillings and Lewandowski article, to provide context for the psychosocial challenges inherent in solid organ transplant, using a number of case examples. Drs. Diane LaPointe Rudow and Jennifer Steel led their team to write a timely paper on the psychosocial evaluation and care of living donors, with specific emphasis on the role of the independent living donor advocate. Dr. Emily Fredericks and her colleagues describe their efforts to evaluate the impact of their quality improvement initiative to enhance outcomes following transfer from pediatric to adult liver transplant care. Finally, Dr. Jim Rodrigue and his collaborators summarize their center's psychosocial outcomes for living kidney donors, which have been used to inform clinical practice and describe challenges associated with donor follow up.

Soon after accepting my invitation to contribute to this special section, Jim informed me that he had served as a guest editor for JCPMS special issue focused on "Psychological Research and Practice in Organ Transplantation" nearly 20 years ago (JCPMS, Vol 3, No 4, 1996)! I read that special issue only after the lion's share of the work was completed on our special section. What I found remarkable about those earlier papers is how spot on many of them remain to this day. Jim also offered up a "Top Ten" list of psychological research needs in transplant. On my read, many of those topics remain current priorities.

Does that mean that not much has changed in transplant psychology in 20 years? I don't think that is true at all. There has been an incredible body of psychosocial transplant research done during that time. In fact, with improving surgical technique and medical follow-up, we are seeing an increased focus on biopsychosocial indicators 
of quality care. Psychologists will continue to play roles in optimal selection of transplant candidates and living donors and in implementation of behavioral interventions to enhance patient adherence to life-long self-care routines, putting us in a position to help reduce the risk of organ rejection and ensure better medical outcomes for these patients. We will also be well served to provide leadership to quality improvement initiatives that monitor and help optimize care of this patient population. Those of us in the field (and those considering it) will be well served by spending the next 20 years contributing to multidisciplinary, evidence-based, psychosocial transplant assessment and care. 